\title{
Understanding population dynamics of a numerically dominant species at hydrothermal vents: a matrix modeling approach
}

\author{
Noreen Kelly $y^{1,2, *}$, Anna Metaxas ${ }^{1}$ \\ ${ }^{1}$ Dalhousie University, Department of Oceanography, 1355 Oxford Street, Halifax, Nova Scotia B3H 4J1, Canada \\ ${ }^{2}$ Present address: York University, Department of Biology, 4700 Keele Street, Toronto, Ontario M3J 1P3, Canada
}

\begin{abstract}
Using a stage-based matrix model, we explored the population dynamics and lifehistory traits of the numerically dominant deep-sea limpet Lepetodrilus fucensis at hydrothermal vents on the Juan de Fuca Ridge, northeast Pacific, to determine the potential mechanisms for the success of this species in an ephemeral and variable ecosystem. The life-history traits of L. fucensis differed from those generally expected for species in fluctuating and unpredictable habitats, in that variation in survival of recruits had the largest effect on population growth, while perturbations in adult survival or fecundity had little influence. However, rapid individual growth rates were also necessary to achieve long-term population growth. The modeled stable stage distribution adequately represented the dynamics of settler and recruit stages, but did not match those of adult stages, in populations sampled from 3 different sites. This suggests that factors not accounted for within the model, such as changing individual behaviour across life stages in response to environmental stimuli, may be important in shaping the structure of $L$. fucensis populations in different microhabitats. In numerical experiments, density-dependent survival and growth of settlers resulted in fluctuations in population growth rate and suppressed total population size over time. Reproductive failure due to parasitic infection decreased local recruitment, but did not result in population extinction. Faster growth rates allowed for population persistence under greater levels of chronic disturbance. Recovery time after a catastrophic disturbance fit within the time frames observed for eruptions in nature. Overall, our analyses emphasize the possible variation in life-history tactics exhibited by organisms in extreme and variable habitats, and demonstrate the high potential of models, originally developed for use in other ecosystems, to accelerate research in deep-sea communities.
\end{abstract}

KEY WORDS: Demography · Recruitment · Growth · Disturbance - Reproductive failure · Density dependence $\cdot$ Variable ecosystem $\cdot$ Deep sea

\section{INTRODUCTION}

Understanding how life-history traits confer demographic success of a species and regulate its population size in the face of environmental variability is a fundamental goal in population ecology. Often, lifehistory traits, demographic parameters and reproductive strategies (e.g. age or size at first reproduction, fecundity, growth, survivorship, larval type, adult life span) are classified based on a species' ability to cope with varying levels of stress and disturbance, in order to explain their persistence in a given environment (Southwood 1988, Winemiller \& Rose 1992). Environmental variation from optimal conditions (e.g. due to a disturbance) may result in a variety of responses at both the individual (e.g. changes in fecundity, growth) and population levels (e.g. changes in population size, settlement, recruitment, survivorship) (Stearns 1992). Thus, knowledge of the life-history characteristics of a species is crucial for predicting the ability of a popula- 
tion to sustain itself and avoid extinction under fluctuating environmental conditions, as well as understanding and predicting the development and maintenance of biological assemblages.

Deep-sea hydrothermal vents are benthic marine habitats with distinctive physical and chemical characteristics which can experience both chronic and catastrophic levels of disturbance. In these habitats, microbes utilize the chemicals present in fluids emanating from deep below the seafloor to derive energy (Karl et al. 1980, Jannasch \& Mottl 1985), which supports unique animal communities that cannot survive elsewhere. In order to access these abundant food resources, organisms have adapted to withstand extremely harsh conditions, including toxic hydrogen sulphides and heavy metals, high temperatures and low oxygen (Johnson et al. 1988, Sarrazin et al. 1999, Butterfield et al. 2004). Large-scale disturbances (i.e. tectonic instability, volcanic eruptions) can result in extinction of invertebrate assemblages over several $100 \mathrm{~m}^{2}$ to $10 \mathrm{~km}^{2}$ by repaving the substratum with fresh lava flows (Haymon et al. 1993, Tunnicliffe et al. 1997, Embley et al. 1999). While these eruptive events are rare (every 10 to $15 \mathrm{yr}$ for fast-spreading centers, less frequently for slow-spreading centers), invertebrate assemblages also experience more frequent disturbances of smaller magnitude (i.e. unpredictable fluctuations in vent fluid, chimney collapse) that occur over sub-annual and subdecadal time scales (Tunnicliffe \& Juniper 1990, Tunnicliffe et al. 1990, Sarrazin \& Juniper 1999).

It has been proposed that species in variable and unpredictable habitats often exhibit short life spans, rapid growth and frequent reproduction, which maximizes population growth and facilitates colonization of new habitats (Southwood 1988, Winemiller \& Rose 1992, McCann \& Shuter 1997). To maintain their populations, hydrothermal vent species must cope not only with unpredictable disturbance regimes, but also with a highly fragmented habitat that is patchily distributed over $10 \mathrm{~s}$ to $100 \mathrm{~s}$ of $\mathrm{km}$ along the mid-ocean ridges. Thus, the life-history traits and population dynamics of vent species may parallel those found in species adapted to other highly disturbed or variable environments (e.g. temporary ponds, tidal pools, intertidal zone), or may differ considerably because of the unique combination of habitat patchiness, disturbance regime and small-scale variations in temperature, toxic chemicals and chemoautotrophic production. Manipulative experiments are uncommon in hydrothermal vent ecology, due to the technical constraints of working in these remote areas, and life-history traits are not well understood for the invertebrate species that inhabit this ephemeral habitat.

Demographic analysis using matrix models has a long history in terrestrial (Leslie 1945, Lefkovitch 1965,
Sondgerath \& Richter 1990, Horvitz \& Schemske 1995) and shallow marine systems (Crouse et al. 1987, Levin \& Huggett 1990, Brault \& Caswell 1993, Lo et al. 1995). Its general use for describing the population dynamics of species with widely different life-history strategies testifies to the flexibility and power of the technique. Matrix population models have become valuable tools in ecology, allowing for the identification of potentially important life-history parameters through sensitivity analyses (Crowder et al. 1994). Their application appears particularly useful in examining the population dynamics of hydrothermal vent species, because few parameters are necessary in order to assemble these models, and because they allow for tests of the sensitivity of population growth to variations in fecundity, growth or survival rates. In addition, they can also be used to conduct numerical experiments for these highly inaccessible populations.

The hydrothermal vent limpet Lepetodrilus fucensis has a ubiquitous distribution along the Juan de Fuca Ridge in the northeast Pacific, where it is the numerically dominant macrofaunal species, exceeding $10^{5}$ individuals $\mathrm{m}^{-2}$ in low-temperature diffuse venting conditions (Chase et al. 1985, Tsurumi \& Tunnicliffe 2001, Bates 2008). L. fucensis possesses distinctive biological characteristics compared to other species of the genus found at hydrothermal vents and cold seeps: higher fecundity and earlier reproductive maturity (Kelly \& Metaxas 2007), the largest body size (McLean 1988), a unique stacking behaviour in vigorous fluid flows (de Burgh \& Singla 1984, Tsurumi \& Tunnicliffe 2003) and chemosynthetic episymbionts on its gills (Bates $2007 \mathrm{a}, \mathrm{b})$, which, alone or in combination, may contribute to its relative success in the vent environment. However, knowledge of $L$. fucensis population dynamics is patchy, as continuous long-term (years) and short-term (weeks to months) observations are currently unfeasible in the vent environment. Understanding its life-history characteristics and population dynamics is crucial to determining the reasons for its success in the ephemeral and variable hydrothermal vent ecosystem. It is within this context that we used matrix models as a tool to identify key life-history stages of $L$. fucensis and explore its population dynamics at Juan de Fuca Ridge hydrothermal vents. As most life-history traits of $L$. fucensis have been measured as a function of body size (i.e. size-at-maturity and fecundity, Kelly \& Metaxas 2007; growth rates and attainment of a size refuge that reduces post-settlement mortality, Kelly \& Metaxas 2008a), we used this empirical information to create a stage class matrix model for L. fucensis. We adopted a prospective approach, using elasticity analyses to identify which life stages had the greatest potential impact on the population growth rate. We also examined population projections under a 
range of biological and geological scenarios, such as variations in growth rates, reproductive failure, density-dependence and partial or complete population extinction due to disturbance.

Few models have been developed to describe population dynamics in the hydrothermal vent environment, in part due to the lack of biological information available for most vent species. Even though the development of models of biological systems at vents is still in an initial stage, such models can significantly advance our understanding of these systems by identifying important parameters and generating alternative predictions, through which we can focus empirical sampling efforts (see Shea et al. 2008 for review). While our modeling efforts represent a first approximation to describing the population dynamics of a hydrothermal vent species, we anticipate that they will establish the use of this modeling approach, and provide a basis for the future use of more complex models, in ecological research at hydrothermal vents.

\section{MATERIALS AND METHODS}

Study sites. The Juan de Fuca Ridge (JDFR) in the northeast Pacific is located 400 to $500 \mathrm{~km}$ off the northwest coast of North America, at the junction of the Pacific and Juan de Fuca tectonic plates $\left(44.5\right.$ to $\left.48^{\circ} \mathrm{N}\right)$ (Lavelle \& Cannon 2001). Lepetodrilus fucensis was sampled using the remotely operated vehicle (ROV) 'ROPOS' from 3 low-temperature diffuse venting sites on the JDFR: (1) Cloud (455 $56^{\prime} 00^{\prime \prime} \mathrm{N}, 1^{\circ} 9^{\circ} 58^{\prime} 53^{\prime \prime} \mathrm{W}$; depth $1525 \mathrm{~m})$ and (2) ROPOS (45 $55^{\prime} 59^{\prime \prime} \mathrm{N}$, $130^{\circ} 0^{\prime} 51^{\prime \prime} \mathrm{W}$; depth $\left.1550 \mathrm{~m}\right)$, both of which are located within Axial Volcano; and (3) Clam Bed (4757' 47" N, $129^{\circ} 5^{\prime} 19^{\prime \prime} \mathrm{W}$; depth $2190 \mathrm{~m}$ ) on the Endeavour Segment. Cloud and ROPOS are separated by $\sim 2 \mathrm{~km}$, while Axial and Endeavour are separated by $\sim 200 \mathrm{~km}$. For the present study, information on the known lifehistory characteristics of $L$. fucensis was assembled from 2 types of subpopulations: established (limpets collected near the vent orifice in 2003) and colonized (limpets that colonized the surfaces of basalt blocks deployed in 2001 and recovered in 2003-which formed part of a larger study on settlement and colonization of hydrothermal vent invertebrates; Kelly et al. 2007). Details of sample collection, processing and measurement are described in Kelly \& Metaxas (2008a).

Matrix model. The model is of the form:

$$
n_{t+1}=\mathbf{A} n_{t}
$$

where $n_{t}$ is a vector of the abundance of individuals in each stage in the population at time $t$ and $\mathbf{A}$ is a population projection matrix (Leslie 1945, 1948, Lefkovitch
1965). The elements of A incorporate the mortality and growth rates and fecundity of each stage class as the probability of surviving but remaining in the same stage $\left(P_{i}\right)$, the probability of surviving and growing to the next stage $\left(G_{i}\right)$ and the reproductive output (fertilities) given as the number of female offspring at time $t+$ 1 produced by adult females at time $t\left(F_{i}\right)$, respectively (Fig. 1) (Caswell 2001). Thus, if the initial stage distribution vector and the projection matrix are known, one can forecast the (female) stage distribution $n_{t+1}$ for a future time $t+1$.

Five stage classes were defined based on sizespecific biological characteristics of Lepetodrilus fucensis (quantified in Kelly \& Metaxas 2007, 2008a): (1) settler ( $\leq 1.00 \mathrm{mmshell}$ length); (2) recruit (1.01 to $3.80 \mathrm{~mm}) ;(3)$ early adult (3.81 to $5.50 \mathrm{~mm})$; (4) mature adult (5.51 to $8.00 \mathrm{~mm}$ ); and (5) old adult (8.01 to 12.00 $\mathrm{mm})$. Settlers are new individuals that experience a period of high mortality, while recruits are individuals that have survived this period but are not yet reproducing. The inclusion of an early adult stage accounts for the observed variation among individuals in sizeat-maturity and the low reproductive output over these shell lengths (Kelly \& Metaxas 2007). Mature adults represent large-sized individuals with high reproductive output, and old adults represent large-sized individuals that are rare in the population but have very high fecundity (McLean 1988, Kelly \& Metaxas 2007).

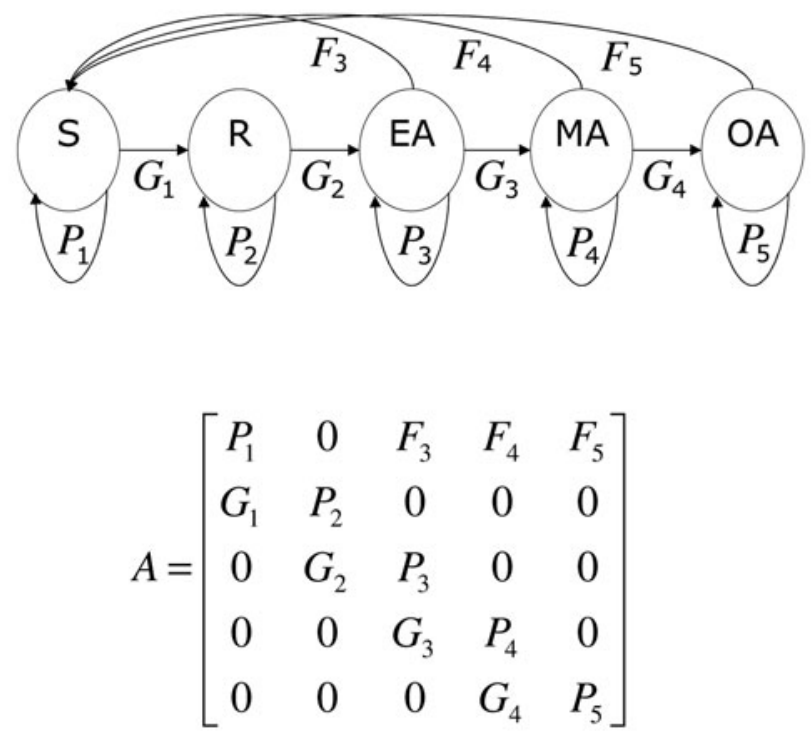

Fig. 1. Lepetodrilus fucensis. Generalized life-cycle diagram and corresponding projection matrix for stage-classified $L$. fucensis. S: settler; R: recruit; EA: early adult; MA: mature adult; OA: old adult. $P_{i}$ : probability of surviving and remaining in stage class $i_{i} G_{i}$ : probability of surviving and growing from stage class $i$ to $i+1 ; F_{i}$ : reproductive output per female in stage class $i$ (where $i=1,2, \ldots 5$ ) 
We assumed that the reproductive contribution of the adults to the next generation represents all potential larval sources (i.e. both local and remote). Given the present understanding of larval dispersal at hydrothermal vents, the magnitude of larval supply from remote sources is unknown but presumed to be low compared to local sources; thus we disregarded allochtonous supply for our model. The transitions among the 5 stages are easily demonstrated in a life-cycle graph, from which the population projection matrix is derived (Fig. 1). The projection matrix elements, $P_{i}, G_{i}$ and $F_{i r}$ were calculated from the stage-specific survival probabilities $\left(\sigma_{i}\right)$, growth probabilities $\left(\gamma_{i}\right)$, stage durations $\left(d_{i}\right)$ and the mean reproductive output of females $\left(m_{i}\right)$ (Crouse et al. 1987, Brault \& Caswell 1993). This model assumes all individuals in a given stage are subject to identical mortality, growth and fecundity schedules.

We estimated $\sigma_{i}$ of Lepetodrilus fucensis using the length-frequency distributions from the established populations collected in 2003 at ROPOS, Cloud and Clam Bed vent sites (Kelly \& Metaxas 2008a). We estimated instantaneous mortality $\left(z_{i}\right)$ over each stage using the combined length-frequency distributions from the 3 vent sites. The populations were adjusted for the number of females, using a 1:1 sex ratio (Bates 2008). The length-frequency distributions were separated into the 5 stage classes based on size and a negative relationship between ln-transformed (female) frequency, and shell length ( $\mathrm{mm}$ ) was confirmed using linear regression (after Frazer 1987). The slope of the regression line for each stage was used as an estimate of mortality over that stage (Fig. S1 in Supplement 1 at www.int-res.com/articles/suppl/m403p113_app.pdf). The stage-specific survival probabilities $\left(\sigma_{i}\right)$ (Table S1 in Supplement 2 at www.int-res.com/articles/suppl/ m403p113_app.pdf) were then calculated as (Vaughan \& Saila 1976, Lo et al. 1995):

$$
\sigma_{i}=\mathrm{e}^{-Z}
$$

In estimating mortality from length-frequency distributions, we assumed that the sampled established populations have reached a stable stage distribution, that mortality remains constant across all shell lengths within each life stage, and that the survival of individual Lepetodrilus fucensis follows a negative exponential function. This method appears to provide a reasonable first approximation for the relationship between life stage and survivorship given that (1) we observed significant negative relationships over most life stages; (2) the error around the relationships was low in most stages; (3) at least one of our established distributions was measured at a stable state (see Supplement 4 and 'Discussion'); and (4) given the narrow range of shell lengths delimiting each of our life stages, the susceptibility to agents of mortality (e.g. predation, com- petition, temperature, sulphide concentrations, etc.) should be similar for all individuals within a stage class.

To calculate $d_{i}$ for each stage, the age of limpets at the stage boundaries was estimated using the linear regression between length-at-day (LAD) and known age of the population (Kelly \& Metaxas 2008a). We assumed a linear relationship as a first approximation to estimating growth in Lepetodrilus fucensis, since we are lacking the high-resolution temporal measurements, as well as concurrent measures of growth and vent fluid properties, currently required to generate more sophisticated growth models (for further discussion see Kelly \& Metaxas 2008a). The difference in age (d) between the smallest size at stage $i+1$ and that at $i$ (for $i=1,2, \ldots 5$ ) yielded an estimate of each $d_{i}$, which was converted into monthly intervals. To examine the effect of variations in limpet growth on population growth rates, 3 different growth scenarios were used; these correspond to differing theoretical levels of exposure to hydrothermal vent fluid along a gradient from low to high flux (e.g. from peripheral to near-vent microhabitats; Bates et al. 2005): (1) slow (9.6 $\left.\mathrm{m} \mathrm{d}^{-1}\right)$; (2) intermediate $\left(19.2 \mu \mathrm{m} \mathrm{d}^{-1}\right)$; and (3) fast (28.8 $\left.\mu \mathrm{m} \mathrm{d}^{-1}\right)$ (Table S1 in Supplement 2).

The probability of an individual growing into the next stage $\left(\gamma_{i}\right)$ was calculated as:

$$
\gamma_{i}=\frac{\left(\frac{\sigma_{i}}{\lambda}\right)^{d_{i}}-\left(\frac{\sigma_{i}}{\lambda}\right)^{d_{i}-1}}{\left(\frac{\sigma_{i}}{\lambda}\right)^{d_{i}}-1}
$$

using an iterative process (Crowder et al. 1994, Caswell 2001), initially setting $\lambda=1$, assembling the projection matrix and recalculating population growth rate $(\lambda)$. This second estimate of $\lambda$ was substituted back into the equation to recalculate $\gamma_{i \text {, }}$ and the iteration stopped when the difference between 2 consecutive values of $\lambda$ was $<0.0001$ (Levin \& Huggett 1990, Lo et al. 1995). $G_{i}$ and $P_{i}$ were calculated from $\sigma_{i}$ and $\gamma_{i}$ as (Crowder et al. 1994, Caswell 2001)

$$
\begin{gathered}
G_{i}=\sigma_{i} \gamma_{i} \\
P_{i}=\sigma_{i}\left(1-\gamma_{i}\right)
\end{gathered}
$$

$F_{i}$ was calculated using the birth-flow equation to represent the continuous reproductive mode of Lepetodrilus fucensis (Kelly \& Metaxas 2007):

$$
F_{i}=\left(\sigma_{1}\right)^{1 / 2}\left[\frac{\left(1+P_{i}\right) m_{i}+G_{i} m_{i+1}}{2}\right]
$$

where $m_{i}$ is the average number of eggs that would become females per adult female of stage $i$ (Levin et al. 1996) and $\sigma_{i}^{1 / 2}$ is the probability of a new offspring sur- 
viving to age $1 / 2$ when it will be counted in $n_{1(t+1)}$ (Caswell 2001). To estimate the mean number of mature eggs that would become females per adult female in each of the 3 reproductive stages (early, mature and old adult), we fitted a power function to the actual fecundity (total number of mature oocytes within the ovary) versus shell length $(\mathrm{mm})$ relationship presented in Kelly \& Metaxas (2007) - actual fecundity $=0.03 \times$ shell length ${ }^{4.82}\left(r^{2}=0.77, p<0.001\right)-$ using the shell length at the midpoint of each stage class to represent the mean fecundity for each stage (Table S1). As the production rate of oocytes in L. fucensis is currently unknown, we assumed every adult female produces eggs at each time step. Kelly \& Metaxas (2007) determined continuous oogenesis for L. fucensis and observed that mature females always contained mature oocytes within the ovary regardless of the time of year they were sampled.

A population projection matrix (Fig. 1), assembled from $P_{i}, G_{i}$ and $F_{i}$, was calculated for each of 3 growth scenarios: slow, intermediate and fast. These 3 individual growth rate scenarios represent the 'basic' calculation. A projection interval from $t$ to $t+1$ of 1 mo was used, this being the minimum single time step for individuals in stage $i$ to advance to stage $i+1$ for all growth scenarios (Vandermeer 1975). Population projections were obtained from numerical simulations of the model, using an initial vector containing 5000 settlers (representing the initial colonization of newly created space) for all population projections. All model analyses were conducted using MATLAB (MathWorks).

Model analysis. The asymptotic population growth rate $(\lambda)$, calculated as the dominant eigenvalue of $\mathbf{A}$ (Caswell 2001), measures demographic success (population growth versus extinction), and the associated right eigenvector, $\mathbf{w}$, describes the stable stage distribution of the population, whereas the left eigenvector, $\mathbf{v}$, describes the reproductive value of each stage in the population. Elasticity analysis was used to investigate the effects of proportional perturbations in elements of the projection matrix to changes in $\lambda$ (de Kroon et al. 1986). Elasticities of $\lambda$ to perturbations in the higherlevel (i.e. $F_{i}, P_{i}, G_{i}$ ) and lower-level (i.e. $\sigma_{i}, \gamma_{i}$ ) parameters were calculated for the projection matrices from each growth scenario.

Populations that are far from reaching their stable stage distribution may be influenced by transient dynamics that differ from asymptotic dynamics, and so affect the accuracy of model predictions in the short term (Horvitz \& Schemske 1995). To examine measures of transient (short-term) dynamics and the rate of population convergence to the stable stage distribution, we calculated the damping ratio $(\rho)$, which is determined by the ratio of the dominant eigenvalue to the first subdominant eigenvalue. The larger the damping ratio, the faster the population is converging towards the stable stage distribution.

To validate the projections from our model, we compared the stable stage distribution obtained from the basic model (the right eigenvector, w) to colonizing populations of Lepetodrilus fucensis sampled in 2003. Length-frequency distributions of these colonizing populations are presented in Kelly \& Metaxas (2008a). An additional sample of an established population was collected from ROPOS vent in 2007 (in the same manner as for previous L. fucensis collections; Kelly \& Metaxas 2008a) to ensure independence from the established populations collected in 2003 which were used to parameterize the model. The colonizing populations from ROPOS, Cloud and Clam Bed in 2003, and the established populations from ROPOS in 2007, were divided into 5 stage classes and expressed as a proportion of the total population within each stage (i.e. relative stage frequency). All stage distributions from colonizing (hereafter referred to as $\mathrm{SD}_{\mathrm{col}}$ ) populations and the established ROPOS 2007 ( $\left.\mathrm{SD}_{2007}\right)$ population were compared to the stable stage distribution obtained from the basic model ( $\mathbf{w}$, referred to as $\mathrm{SD}_{\text {mod }}$ for comparison to other stage distributions) under slow, intermediate and fast individual growth scenarios using a $G$-test and an index of proportional similarity (PS) to determine the magnitude of the difference between the 2 distributions (Horvitz \& Schemske 1995).

Theoretical population projections. Larval mortality: While a larval stage was not included in the model because of the paucity of information on the demographic parameters of this life stage in hydrothermal vent species, Eq. (6) incorporates an approximate measure of larval mortality: the probability of a new individual surviving to stage $1 / 2\left(\right.$ e.g. $\left.\sigma_{1}{ }^{1 / 2}\right)$ when it would be counted in $n_{1(t+1)}$ (Caswell 2001). However, larval mortality of Lepetodrilus fucensis may actually be much higher than is accounted for by the model. For example, mortality estimates of planktonic larval stages of shallow-water benthic invertebrates as high as $80 \%$ have been recorded (Morgan 1995). We examined the effect of larval mortality on $\lambda$ and $\mathbf{w}$ under all 3 individual growth scenarios (slow, intermediate and fast) by reducing new offspring survival probability $\left(\sigma_{1}{ }^{1 / 2}\right)$ by 50 and $99.5 \%$ (chosen arbitrarily) of the original value calculated using Eq. (6).

Density dependence: Kelly \& Metaxas (2008a) suggested density-dependent effects may be influencing the abundance of settlers at JDFR vent sites. In the present study, we further explored this potential effect on the population dynamics of Lepetodrilus fucensis by incorporating a density-dependent survival function into the matrix elements affecting the settler stage survival probability $\left(\sigma_{1}\right)$ as: 


$$
S=\frac{1}{1+e^{\frac{N_{\mathrm{r}}}{A}-B}}
$$

where $N_{\mathrm{r}}$ is the remaining population size (total population size - numbers of settlers) at time $t$ (after Pennycuick et al. 1968). The values of $A$ and $B$ were varied to give 3 different shapes to the survival function, where larger values of $B$ yield a steeper curve in the region of $N_{\mathrm{r}}=500$ : (1) strong density dependence $(A=50, B=$ $10)$; (2) moderate density dependence $(A=150, B=$ 3.3333); and (3) weak density dependence $(A=400$, $B=1.25$ ). To compare the different curves, the values of $A$ and $B$ in all cases were chosen to satisfy $A B=500$, which yields a survival value $S=0.5$ at $N_{\mathrm{r}}=500$ (Usher 1971). Total population size and $\lambda\left(\mathrm{mo}^{-1}\right)$ for each density-dependence scenario at each of the intermediateand fast-growth scenarios were compared to the basic model results for each growth scenario (we did not include the slow growth scenario, as $\lambda<1$ for the basic model).

Disturbance: Throughout the JDFR hydrothermal vent system, changes in vent faunal community structure occur in response to variations in both the spatial and temporal extent of disturbance events. Frequent disturbances that occur over weeks to months, such as unpredictable fluctuations in vent fluids caused by turbulent mixing, tides and/or bottom currents or substratum instabilities, may only affect some proportion of the community across $\mathrm{cm}$ to $\mathrm{m}$ patches (Tunnicliffe \& Juniper 1990, Tunnicliffe et al. 1990, Tivey et al. 2002, Sarrazin \& Juniper 1999). In contrast, rare disturbances that occur over $100 \mathrm{~m}^{2}$ to $10 \mathrm{~km}^{2}$, such as earthquake swarms that alter the chemical and thermal properties of venting fluid, or eruptive events that repave the substratum with fresh lava flows, have occurred at different locations along the JDFR roughly every $5 \mathrm{yr}$ (Tunnicliffe et al. 1997, Embley et al. 1999, www.pmel. noaa.gov/vents/geology/submarine_eruptions.html). These events may result in the complete or nearcomplete extinction of invertebrate assemblages at affected sites (Marcus et al. 2009). We explored the influence of 2 distinct disturbance scenarios on total population size of Lepetodrilus fucensis after $5 \mathrm{yr}$ of projection: (1) a high frequency, low magnitude disturbance (chronic), and (2) a low frequency, high magnitude disturbance (catastrophic). For the chronic disturbance scenario, we examined the threshold level of population reduction that would cause population extinction by incrementally removing a percentage of the population in each stage (same percentage across all stages) in each time step until the population trajectory declined. For the catastrophic disturbance scenario, we removed $99 \%$ of the total population size after the first year of projection and examined the time for the population size to equal or exceed the pre- disturbance level. We compared these 2 disturbance scenarios to the basic model scenarios without disturbance, as well as under 3 levels of density dependence (strong, moderate and weak), for 2 individual growth scenarios (intermediate and fast).

Reproductive failure: Recently, Tunnicliffe et al. (2008) showed that the parasitic infection of Lepetodrilus fucensis by a chitinophilid copepod resulted in the decline and/or cessation in reproductive output in infected individuals. However, they also found a significantly greater incidence of infection within larger (>5 mm) females, and while the overall incidence of infection across all sites was only $5 \%$, incidence in females reached nearly $30 \%$ at 1 location, the Clam Bed site on the JDFR (Tunnicliffe et al. 2008). To examine the effect of female castration due to parasitic infection on total population size, we prevented 5 and $30 \%$ of females in all 3 adult stages from contributing to the next generation during each time step. The change in total population size at the end of $5 \mathrm{yr}$ of population projection was compared between uninfected and infected states for the basic model and 3 levels of density dependence (strong, moderate and weak) for both intermediate and fast growth scenarios.

\section{RESULTS}

Projection matrices were assembled for the Lepetodrilus fucensis populations under 3 different growth scenarios that depicted differences in individual growth rates. The dominant eigenvalue $\left(\lambda, \mathrm{mo}^{-1}\right)$ indicated that under slow individual growth rates, the population declines $(\lambda=0.94)$, but under intermediate $(\lambda=1.23)$ and fast $(\lambda=1.58)$ individual growth rates, the population increases (for projection matrices, see Table S2 in Supplement 2; for uncertainty analysis of $\lambda$, see Supplement 3 at www.int-res.com/articles/ suppl/m403p113_app.pdf).

The settler and recruit stages comprised the greatest percentage of the total population under all 3 individual growth scenarios (Table S3, in Supplement 2). However, w for the fast individual growth rate scenario had a greater proportion of the population in adult stages compared to the intermediate- and slowgrowth scenarios. The damping ratios were high (1.530, 1.771 and 1.769 for slow, intermediate and fast individual growth scenarios), indicating a rapid convergence ( 6 to $8 \mathrm{mo}$ ) to the stable stage distribution. In all 3 growth scenarios, v increased with stage, and the greatest contribution to the next generation was from the old adult stage. However, reproductive value declined across all life stages as individual growth rates increased (Table S3). 
Population growth rate $(\lambda)$ was most sensitive to perturbations in $P_{i}$ for recruit and early adult stages under slow and intermediate individual growth scenarios (Fig. 2A). For $G_{i}$ elasticity of $\lambda$ was most sensitive to perturbations for the settler and recruit stages under slow and intermediate individual growth rates, and for the settler, recruit and early adult stages under fast individual growth rates. Elasticity of $\lambda$ was also sensitive to changes in $F_{i}$, but only for the mature and old adult stages under the fast individual growth scenario. As growth rate increased, perturbations in $G_{i}$ had a greater effect on

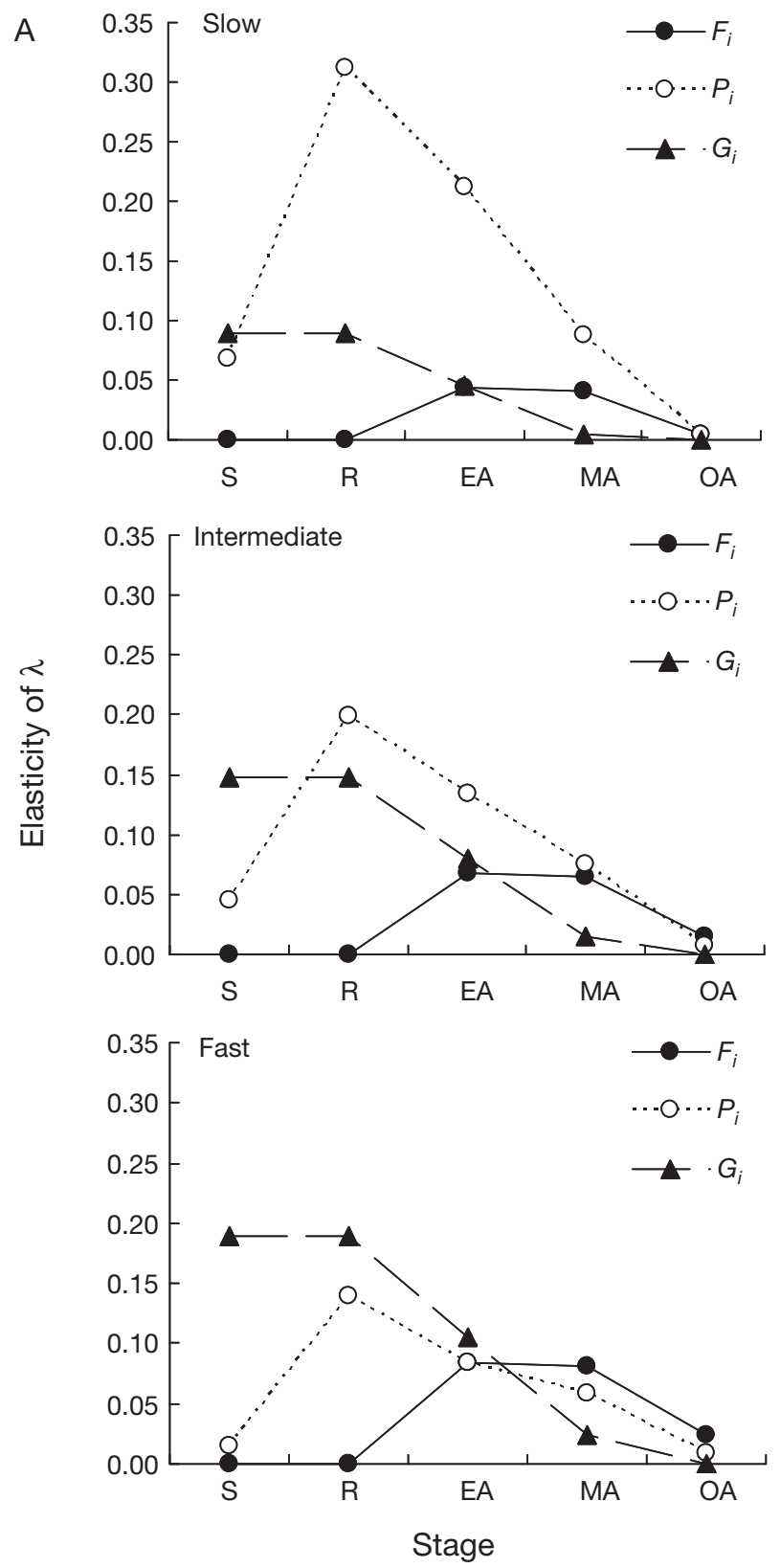

$\lambda$, and perturbations in $P_{i}$ became less important for the settler, recruit and early adult stages, while $F_{i}$ became more important for the mature and old adult stages (Fig. 2A). Elasticities for $\sigma_{i}$ were much greater in absolute value than those for $\gamma_{i}$ and thus had a greater overall effect on $\lambda$ (Fig. 2B). $\lambda$ was most sensitive to perturbations in $\sigma_{i}$ for the recruit stage, under all individual growth rate scenarios.

Under all 3 individual growth scenarios, the $\mathrm{SD}_{\bmod }$ closely matched the $\mathrm{SD}_{\text {col }}$ (Table 1, Fig. 3). Proportional similarities indicated that the differences between the $\mathrm{SD}_{\text {mod }}$ and $\mathrm{SD}_{\text {col }}$ were small (mean $\pm \mathrm{SD}=86.3 \pm 6.3 \%$,

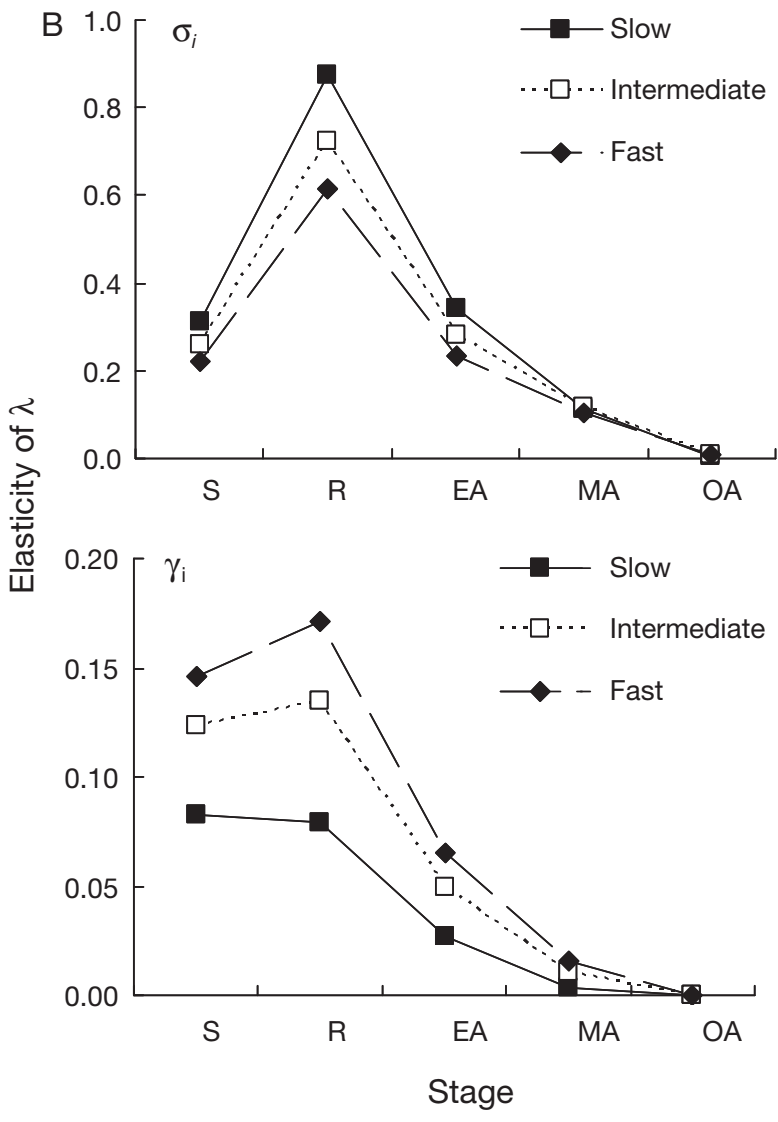

Fig. 2. Lepetodrilus fucensis. Elasticity of population growth rate $\left(\lambda, \mathrm{mo}^{-1}\right)$ to $(\mathrm{A})$ perturbations in $P_{i}, G_{i}$ and $F_{i}$ of the population projection matrix A and (B) changes in stage-specific survival probability $\left(\sigma_{i}\right)$ and stage-specific growth probability $\left(\gamma_{i}\right)$ for 3 different individual growth scenarios: slow, intermediate and fast. S: settler; R: recruit; EA: early adult; MA: mature adult; OA: old adult 
Table 1. Statistics used to measure agreement between the stage distributions of populations of Lepetodrilus fucensis predicted from the basic model ( $\left.\mathrm{SD}_{\mathrm{mod}}\right)$ for 3 individual growth scenarios (slow, intermediate and fast) for: (1) colonizing populations $\left(\mathrm{SD}_{\mathrm{col}}\right)$ collected from colonization experiments in 2003 at ROPOS, Cloud and Clam Bed vent sites; and (2) an established population collected from ROPOS vent site in $2007\left(\mathrm{SD}_{2007}\right)$. The $G$-statistic indicates a significant difference between the 2 distributions, and the proportional similarity (PS) index indicates the magnitude of the similarity between the 2 distributions. Stage distributions are presented in Figs $3 \& 4 .{ }^{*}: \mathrm{p}<0.05$; $^{* *}: \mathrm{p}<0.01(\mathrm{df}=4$ for all comparisons)

\begin{tabular}{|c|c|c|c|c|c|c|}
\hline \multirow[t]{2}{*}{ Population } & \multicolumn{3}{|c|}{$\longrightarrow G$} & \multicolumn{3}{|c|}{$\longrightarrow$ PS $(\%)$} \\
\hline & Slow & Intermediate & Fast & Slow & Intermediate & Fast \\
\hline \multicolumn{7}{|l|}{ Colonizing } \\
\hline ROPOS & $11.4^{*}$ & $11.4^{*}$ & $11.5^{*}$ & 92.5 & 86.2 & 82.6 \\
\hline Cloud & $10.1^{*}$ & 8.97 & 8.51 & 85.8 & 93.7 & 94.7 \\
\hline Clam Bed & $11.5^{*}$ & $12.1^{*}$ & $12.4^{*}$ & 87.7 & 79.9 & 76.1 \\
\hline \multicolumn{7}{|l|}{ Established } \\
\hline ROPOS 2007 & $15.5^{* *}$ & $15.3^{* *}$ & $15.1^{* *}$ & 20.8 & 23.8 & 24.2 \\
\hline
\end{tabular}

$\mathrm{n}=9$ ), despite having all but 2 of the $\mathrm{SD}_{\text {col }}$ differ significantly from the $\mathrm{SD}_{\text {mod. }}$ In contrast, the $\mathrm{SD}_{\text {mod }}$, under all 3 individual growth scenarios, were significantly different from $\mathrm{SD}_{2007}$, and PS values were below 25\% (Table 1, Fig. 4).

Reducing larval survival probability by 50 and $99.5 \%$ of the original value calculated using Eq. (6) reduced the overall population growth rate for all 3 growth scenarios, but the largest changes in $\lambda$ occurred under fast individual growth rates (Fig. 5). Lowered larval survival probability also shifted the stable stage distribution, decreasing the proportion of settlers in the population, but increasing the proportion of individuals in successive stages (Table S4 in Supplement 2).

To examine the effects of density-dependent survival and growth of settlers, a survival function was applied to $\sigma_{1}$, and changes in $\lambda$ and in total population size were forecast over $5 \mathrm{yr}$. Under both intermediate and fast individual growth rates, $\lambda$ converged to $\sim 1$ for moderate and weak density dependence, resulting in a stable population size of $\sim 10^{4}$ individuals within $1 \mathrm{yr}$ (Fig. 6). Strong density dependence led to the largest fluctuations in $\lambda$ and suppressed the total population size to the lowest levels after 1 yr (Fig. 6).

For the catastrophic disturbance scenario, recovery time for the basic model was shorter when individuals grew faster, as expected. However, population recov-

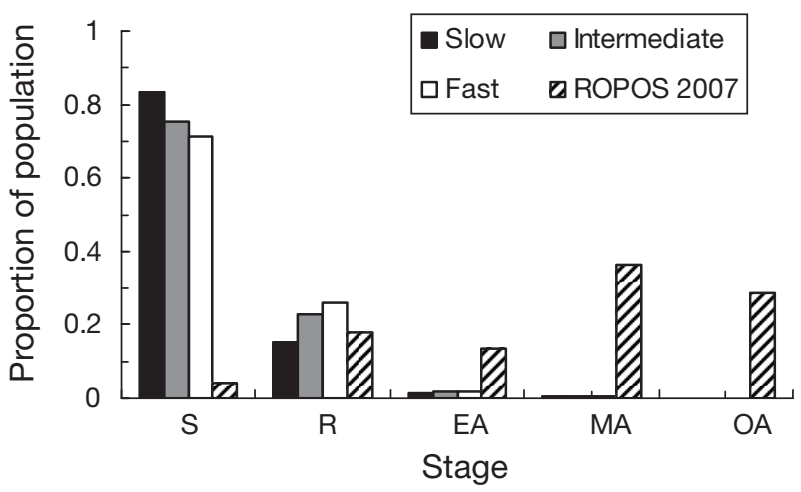

Fig. 4. Lepetodrilus fucensis. Proportion of population by stage class for the established L. fucensis population collected from ROPOS vent site in $2007\left(\mathrm{SD}_{2007}\right)$, compared to the stable stage distribution $\left(\mathrm{SD}_{\bmod }\right)$ predicted from the basic model, for 3 individual growth scenarios: slow, intermediate and fast. S: settler: R: recruit: EA: early adult: MA: mature adult:

\footnotetext{
OA: old adult
}

Fig. 3. Lepetodrilus fucensis. Proportion of population by stage class for colonizing $L$. fucensis populations collected from experiments in 2003 at ROPOS, Cloud and Clam Bed vent sites, compared to the stable stage distribution predicted from the basic model, for 3 individual growth scenarios (slow, intermediate and fast). S: settler: R: recruit: EA: early adult: MA: mature adult: OA: old adult 


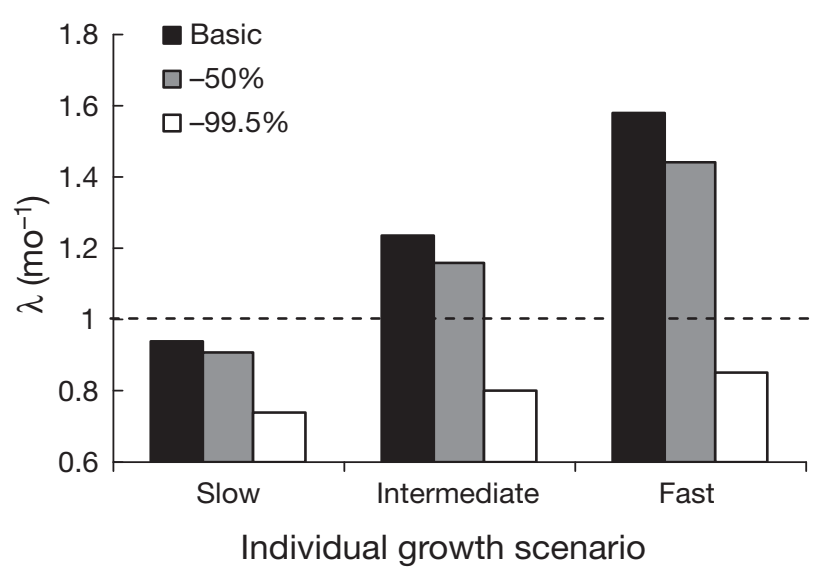

Fig. 5. Lepetodrilus fucensis. Change in the population growth rate $(\lambda)$ when larval survival probability $\left(\sigma_{i}^{1 / 2}\right)$ is reduced by 50 and $99.5 \%$ of the value used in the basic model for each of 3 individual growth scenarios (slow, intermediate and fast). Dashed line indicates $\lambda$ of a stable population ery was longer under all levels of settler density dependence than for the basic model, for both individual growth scenarios (Fig. 7A). For the chronic disturbance projections, the threshold reduction level causing population decline for the basic model was greater when individuals grew faster (Fig. 7B). Under weak and moderate settler density dependence, the threshold reduction level was slightly decreased relative to the basic model, but there was no difference under strong density dependence (Fig. 7B).

Settler density-dependence also reduced the negative effects of reproductive failure due to parasitic infection on total population size after $5 \mathrm{yr}$, compared to the projections in the absence of density dependence (Fig. 7C). While the reduction in total population size due to parasitic infection was similar under intermediate and fast individual growth, increasing the incidence of infection increased the effect on total population size (Fig. 7C).

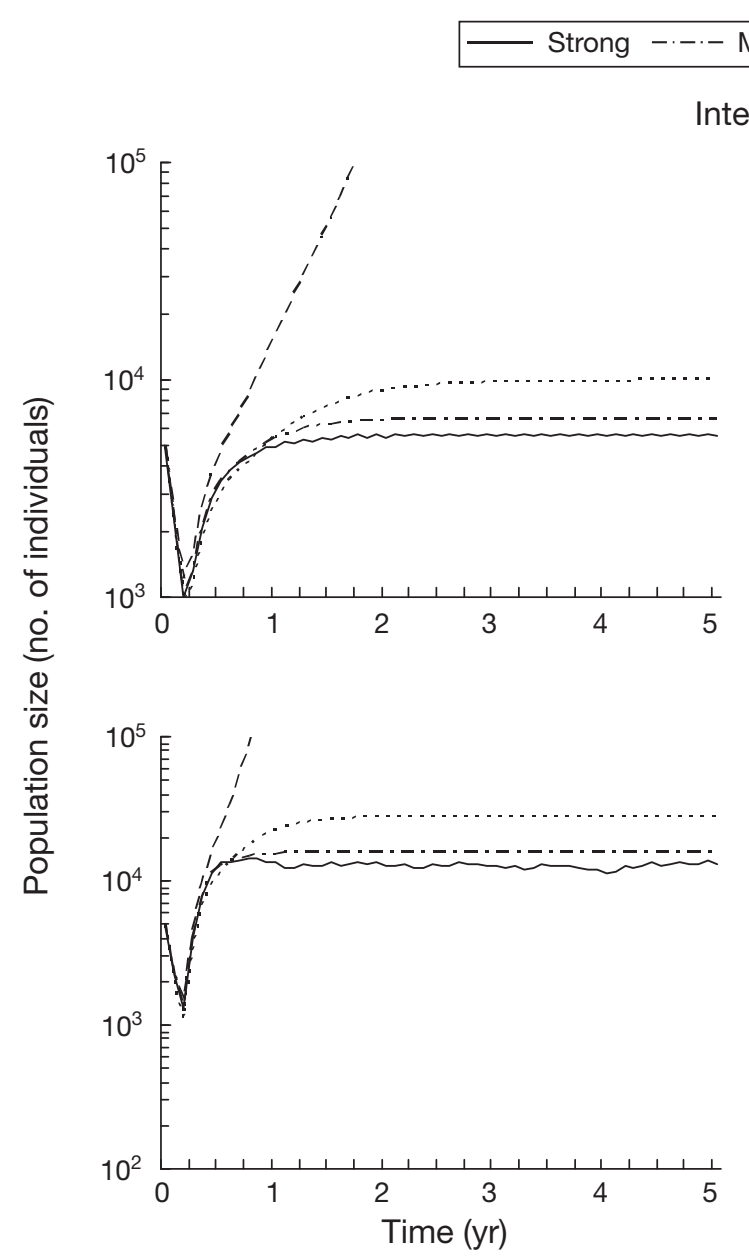

Fig. 6. Lepetodrilus fucensis. Total population size (no. of individuals) and population growth rate $\left(\lambda, \mathrm{mo}^{-1}\right.$ ) over $5 \mathrm{yr}$ of population projection for the basic model and 3 scenarios of settler density-dependent survival (strong, moderate and weak) and 2 different individual growth rates (intermediate and fast) 


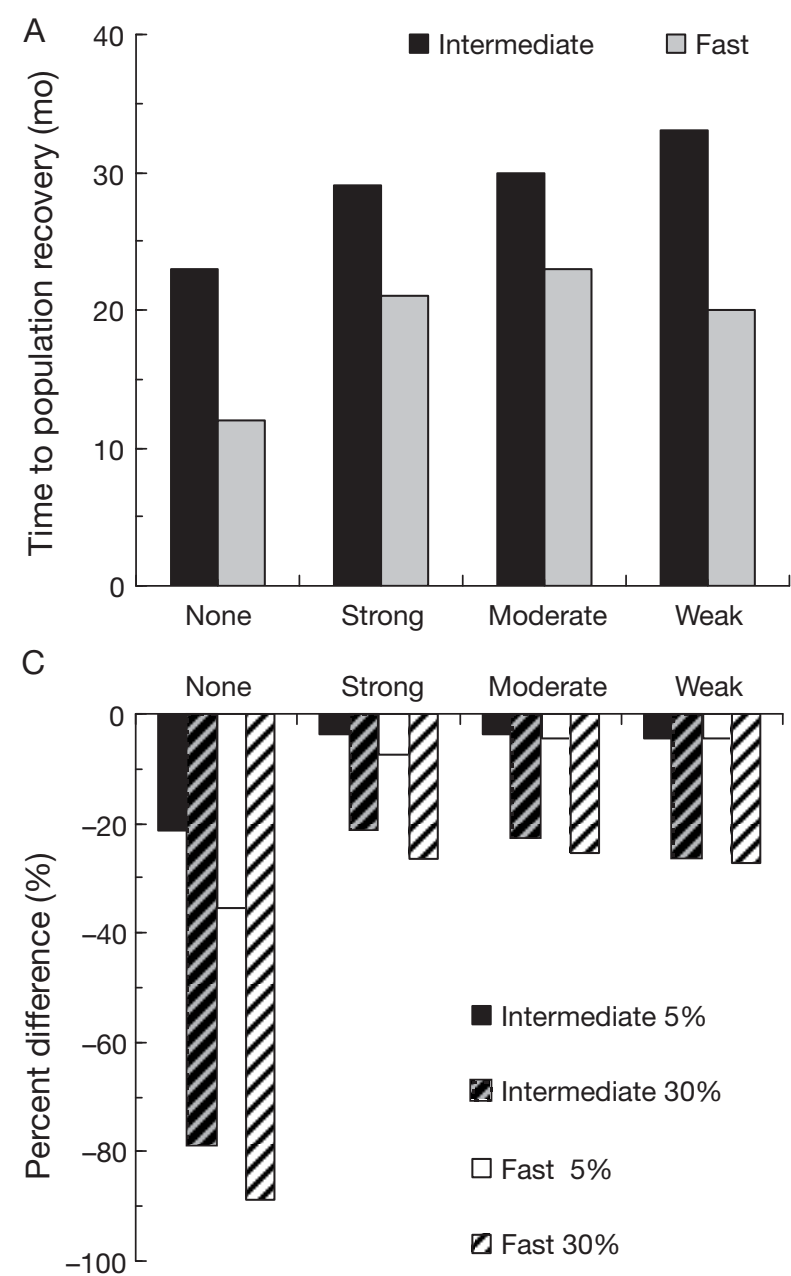

Level of settler density-dependence

\section{Lepetodrilus fucensis demography}

We have explored the life-history traits and population dynamics of a numerically dominant benthic invertebrate in a highly variable and unpredictable habitat. Based on our model, rapid growth and high recruit survival were the most significant life-history traits allowing the success of Lepetodrilus fucensis in the ephemeral and harsh hydrothermal vent environment. Life-history characteristics such as rapid growth, early maturation and frequent reproduction are common for species in fluctuating and unpredictable habitats (Winemiller \& Rose 1992, McCann \& Shuter 1997, Ramirez Llodra 2002). The combination of rapid growth and high juvenile survival with early maturation and frequent reproduction, would maximize the intrinsic rate of population increase at the expense of mean generation time, allowing rapid recolonization of habi-

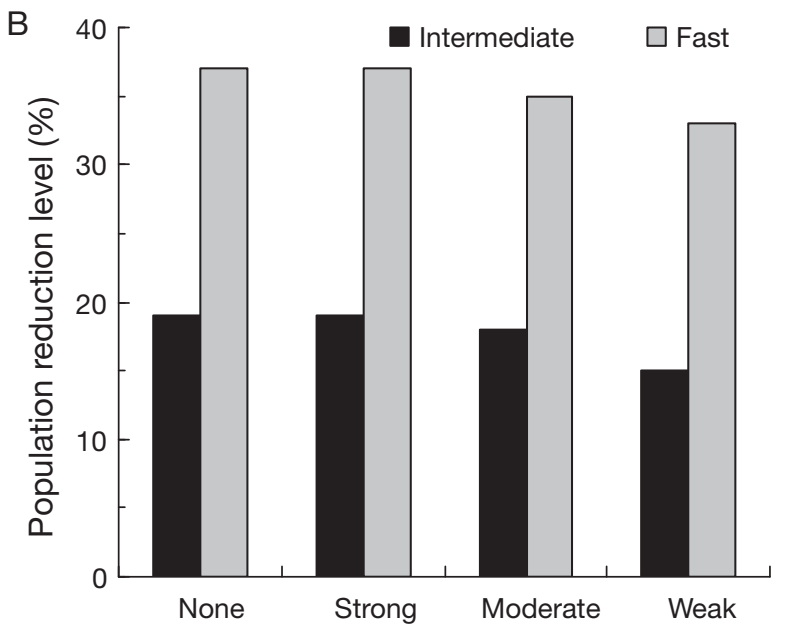

Fig. 7. Lepetodrilus fucensis. Effects of model manipulation on population characteristics during theoretical projections under varying levels of density dependence (strong, moderate and weak) and individual growth scenarios (intermediate and fast). (A) Recovery time (mo) for L. fucensis populations after catastrophic disturbance; (B) threshold percentage of population reduction per time step resulting in population extinction for the chronic disturbance scenario; and (C) percent difference (from baseline model) in total population size after $5 \mathrm{yr}$ of population projection due to reproductive failure of 5 or $30 \%$ in the mature adult and old adult stages

tats and recovery from repeated disturbance, and ultimately enabling persistence in highly disturbed and unpredictable environments (Winemiller \& Rose 1992, McCann \& Shuter 1997).

Based on prospective elasticity analyses, the dynamics of the early life-history stages of Lepetodrilus fucensis are potentially the most important to population growth, and thus any variation in these life-history stages may be most influential to its success. In hydrothermal vent habitats, unpredictable fluctuations in the physico-chemical environment (e.g. temperature, $\mathrm{O}_{2}, \mathrm{H}_{2} \mathrm{~S}$ ) (Johnson et al. 1988, Chevaldonne et al. 1997, Sarrazin et al. 1997, Sarrazin et al. 1999, Tivey et al. 2002), as well as variations in habitat complexity (Kelly \& Metaxas 2008b), available substratum space (Tsurumi \& Tunnicliffe 2003) or access to food resources (Levesque et al. 2003), may influence survival and growth of early life-history stages of $L$. fucensis. Changes in habitat conditions during settlement or between successive settlement pulses within a vent 
site could result in variations in growth of settlers, influencing subsequent recruitment. In addition, the low elasticities observed for $P_{i}$ and $F_{i}$ also indicate that processes such as predation or competition occurring during the post-settlement stages would be more important to the population dynamics of L. fucensis than those occurring during adult life.

While habitat characteristics can shape the lifehistory strategies of an organism, more than a single evolutionary response is possible, permitting divergent life-history traits to coexist in the same types of habitats (Southwood 1988). For benthic marine invertebrates with complex life-cycles, the highest mortality is commonly thought to occur within the early lifehistory stages (Hunt \& Scheibling 1997); for Lepetodrilus fucensis, however, settler survivorship was low, while recruit survivorship was highest among all life stages. Several hypotheses may account for the large relative difference in survival between settlers and recruits. First, larger sized limpets $(>1.0 \mathrm{~mm})$ may outcompete settlers for space, food and/or access to vent flows, or contribute to the accidental mortality of settlers (e.g. 'bulldozing', Micheli et al. 2002). Second, settlers may be more susceptible to the physical and/or chemical properties of the venting fluid, and thus experience conditions which exceed their physiological tolerances more frequently, resulting in higher mortality than recruits. At JDFR vents, Kelly \& Metaxas (2008a) demonstrated a negative relationship between temperature and settler abundance but a positive one with abundance of adults. Regardless of the source of mortality, the present study demonstrates that low survival through the settlement stage influences the supply of individuals to all subsequent stages, while high recruit survival ensures relatively constant, albeit low, recruitment rates of L. fucensis into the adult population.

Rapid individual growth rates of Lepetodrilus fucensis were necessary to achieve long-term population growth. Interestingly, the individual growth rates used for L. fucensis in the intermediate and fast growth scenarios are comparable to those of other vent species (e.g. Lutz et al. 1985, 1994, Tunnicliffe et al. 1997, Kelly \& Metaxas 2008a). Conditions at hydrothermal vents are ideal to support rapid growth of benthic invertebrates, as chemosynthetic microbial primary production is high in diffusely venting conditions (Karl et al. 1980, Jannasch \& Mottl 1985). Rapid individual growth would be an advantageous trait for a species that inhabits an unstable and ephemeral environment; higher individual growth rates would reduce the time spent within stages that have low probabilities of survival and increase the probability of an individual reaching sexual maturity, ultimately preventing population extinction.
Transient dynamics do not appear to differ greatly from the long-term asymptotic dynamics, as the damping ratio was high under all 3 individual growth scenarios. In an analysis of transient population dynamics of various species, Koons et al. (2005) found that the transient dynamics varied little from long-term asymptotic dynamics for short-lived, fast-reproducing species. However, they also caution against conducting matrix demographic analysis under the assumption of a stable population state, unless it can be empirically justified (Koons et al. 2005). It is possible that fluid fluctuations and disturbances present within the hydrothermal vent environment prevent invertebrate populations in these systems from converging upon their stable stage distribution. However, we found no significant difference between the length-frequency distributions of established Lepetodrilus fucensis populations sampled at the ROPOS vent site in 2003 and 2007 (Kolmogorov-Smirnov 2-sample test, $D=0.072$, p > 0.01; Fig. S2 in Supplement 4 at www.int-res.com/articles/ suppl/m403p113_app.pdf). The assumption of a stable population state appears to be valid for our model, but is likely valid only at low-temperature diffuse vents that exhibit no or relatively small long-term changes in vent fluid output.

Under all individual growth rate scenarios, the stable stage distribution of the basic model $\left(\mathrm{SD}_{\mathrm{mod}}\right)$ closely approximated the stage distributions of colonizing populations of Lepetodrilus fucensis $\left(\mathrm{SD}_{\mathrm{col}}\right)$, but not those of established populations from ROPOS in 2007 $\left(\mathrm{SD}_{2007}\right)$. In the basic model, the combination of very high $F_{i}$ values in the old adult stage and high $P_{i}$ but low $G_{i}$ values in the settler and recruit stages led to a large number of settlers entering the population in each time step and the accumulation of settlers and recruits within the population over time. In comparison, colonizing populations collected from ROPOS, Cloud and Clam Bed vent sites had $\leq 2$ yr to develop, also allowing for the accumulation of many small (young) but few large (older) individuals. In contrast, the established population sampled from ROPOS vent in 2007 had much longer to develop, allowing more time for adults to accumulate within the population, but included fewer settlers. This suggests that either most life-history parameters of $L$. fucensis change as individuals age, such that older, more established populations exhibit different dynamics from younger populations, or that factors in addition to growth, fecundity and mortality, and which are not accounted for in the model, are regulating the observed structure of $L$. fucensis populations.

Colonizing populations of Lepetodrilus fucensis were sampled $\sim 25 \mathrm{~cm}$ from the vent orifice, where temperature and fluid flux can be more variable, while established samples were taken directly adjacent to 
the venting source, where the flux of temperatures and chemicals within the vent fluid is more constant (Bates et al. 2005). Bates (2008) and Kelly \& Metaxas (2008a) observed a size-based segregation of $L$. fucensis in relation to distance from fluid source at lowtemperature diffuse vents, suggesting that settlement occurs in more peripheral areas ( $>25$ to $50 \mathrm{~cm}$ from the vent source), and that recruits and/or early adults may migrate to near-vent areas ( $<25 \mathrm{~cm}$ from vent source). This migration may be triggered by symbiont acquisition and increasing sulphide requirements with increasing body size (Bates 2007b) or may function to maximize reproductive output (Kelly \& Metaxas 2007). Migration away from settlement sites would alter the size-structure of the population observed in both peripheral and near-vent microhabitats, resulting in large numbers of settlers in the former, and high abundance of adults in the latter. This pattern may also explain the low number of settlers within the established populations, despite the high reproductive output of adults. Size-selective migration between different microhabitats would alter the distribution of observed populations, influencing estimates of $\sigma_{i,}$ and possibly the growth of individuals, affecting the estimates of $d_{i}$. The changing behaviour of $L$. fucensis across life-history stages may play a large role in its success at JDFR vent sites.

\section{Theoretical population projections}

Decreasing larval survival probability by $50 \%$ reduced the overall population growth rate, and a reduction of $99.5 \%$ resulted in population decline for all 3 growth scenarios. While high larval mortality is characteristic of most benthic marine invertebrates with a dispersive larval stage, no estimates of larval mortality in hydrothermal vent systems are currently available, although mortality is presumed high. Sources of mortality for dispersing vent larvae may be similar to those of their shallow-water counterparts, and include, but are not limited to, predation and starvation or depletion of energy reserves (reviewed in Morgan 1995). In addition, dispersal through cold bottom waters may slow the metabolism and lengthen development time of vent larvae (Berg 1985, Pradillon et al. 2001), but longer dispersal times increase the risk of being transported off-axis and lost from the ridge system (Marsh et al. 2001, Thompson et al. 2003). Alternatively, at Axial Volcano, survival of vent larvae may be high, as the combination of local relief and hydrodynamics may facilitate larval retention (Metaxas 2004). Incorporation of a larval stage into our model, when more information on growth and development becomes available, would permit us to refine estimates of larval mortality. In turn, quantifying the effect of larval survival and rates of dispersal on population growth will ultimately enable the use of more complex models that link dispersal and demography of hydrothermal vent species (e.g. Neubert \& Caswell 2000, Neubert et al. 2006).

While our basic model forecasted population size using exponential growth, including the effects of density-dependent survival and growth into the settler stage generated more realistic population trajectories for Lepetodrilus fucensis, with intermediate and fast individual growth rates causing convergence and oscillations in $\lambda$ over time, respectively. Densitydependent processes acting on $L$. fucensis settlers may be the result of variations in competition and/or increased mortality within near-vent microhabitats. Mullineaux et al. (2003) proposed that the relative intensity of negative interactions, such as predation, inhibition and competition, should be most prominent in areas where vent fluid flux and faunal densities are highest. For $L$. fucensis, adults may outcompete settlers at nearvent microhabitats for space and/or resources, inhibiting subsequent growth, or cause 'accidental' mortality (e.g. bulldozing) of settlers, essentially restricting them to microhabitats on the periphery where such negative interactions would be less intense. However, recent studies of shallow-water invertebrates have shown that population dynamics are driven by the combined interaction of density-dependent and environmental factors (Higgins et al. 1997, Lima \& Defeo 2000). Kelly \& Metaxas (2008a) reported a relationship between L. fucensis life-history stage and temperature, suggesting that thermal tolerance is lowest during the settler stage and increases with increasing body size. It is likely that a combination of both exposure to environmental conditions and high adult abundances is driving the lack of settlers in near-vent microhabitats.

The time frame for Lepetodrilus fucensis population recovery after catastrophic disturbance for the basic model was similar to the time frames observed for recovery of other vent species after eruptions on the East Pacific Rise (e.g. 11 and 21 mo for the tubeworms Tevnia jerichonana and Riftia pachyptila, respectively; Shank et al. 1998) and the JDFR (e.g. $\leq 2 \mathrm{yr}$ for one third to one half of the regional vent species pool; Tunnicliffe et al. 1997, Tsurumi \& Tunnicliffe 2001). Including the effects of settler density dependence in the catastrophic disturbance scenario slowed population recovery compared to the basic model, but still fit within observed time frames, particularly under fast individual growth. For the chronic disturbance scenario, the proportion of population reduction at each time step increased with increasing individual growth. However, the threshold for $L$. fucensis population persistence was lower under scenarios that included set- 
tler density-dependence, due to the combination of negative biological and physical effects on the population. These results suggest that fast individual growth, frequent reproduction and early maturation allow for large numbers of propagules and, consequently, rapid recolonization of new habitats or newly created space and rapid recovery of populations from chronic and catastrophic disturbance.

Parasitic castrators may regulate host population size, as they have a direct influence on the reproductive output of their hosts (Blower \& Roughgarden 1987, Lafferty 1993). Tunnicliffe et al. (2008) postulated that parasitic infection may be a limiting factor for the reproductive and competitive success of local populations of Lepetodrilus fucensis at JDFR vents, since large females, which contribute most to the next generation, are disproportionately infected. Reduced reproductive output of $L$. fucensis caused a decrease in final population size at the end of $5 \mathrm{yr}$, with a greater decline under fast individual growth scenarios, most likely because of the reduced time individuals spent in adult stages. However, no reproductive failure scenario resulted in population extinction, even when the incidence of infection was highest $(30 \%)$. This is not surprising given the low elasticity values for $F_{i}$. Other environmental conditions can also result in poor reproductive performance; for example, extremely high rates of reproductive failure have been observed in other mollusc populations, resulting from exposure to harmful algal blooms (Tracey 1988) or environmental toxins (Gibbs \& Bryan 1986). For $L$. fucensis, poor venting conditions, such as at waning or senescent vents, have also been shown to affect reproductive output (Kelly \& Metaxas 2007), and in these cases reproductive failure may exceed $30 \%$. Reducing reproductive output by up to $90 \%$ further reduced total population size, but still did not result in population extinction. Thus it appears that while high levels of reproductive failure in L. fucensis can reduce both the production of offspring and population size, continuous reproductive output ensures this species' success in the vent system.

\section{Model limitations}

The use of deterministic matrix models requires the simplifying assumption of a stable stage distribution, with time-invariant vital rates (Caswell 2001). It is possible that fluid fluctuations and disturbances in the hydrothermal vent environment prevent invertebrate populations in these systems from converging upon their stable stage distribution, resulting in survival and growth probabilities within the projection matrix that are no longer constant over time (Vandermeer 1975).
However, given the stability we observed in the population distributions at ROPOS vent over a $5 \mathrm{yr}$ period (Fig. S2 in Supplement 4), variations in the vital rates may only be relevant for populations inhabiting vent sites that exhibit frequent or relatively large long-term changes in disturbance or vent fluid output.

Due to sampling limitations, it was necessary to make several simplifying assumptions regarding the timing and nature of biological events in the life cycle of Lepetodrilus fucensis, such as the frequency of reproduction, the linearity in growth rate and a constant mortality rate. Elasticity values for the reproductive contribution from adults and growth transitions were consistently small, suggesting that violations of our assumptions concerning fecundity, stage duration and/ or exclusion of a larval stage would have little effect on the population growth rate. However, incorporating non-linear growth rates in the model would change the relative stage durations, particularly if growth slows as an organism ages, resulting in a model stage distribution containing greater numbers of adults and fewer settlers and recruits, potentially more closely resembling established rather than colonizing population distributions.

In contrast, given the high elasticity values for survivorship, particularly for the settler and recruit stages, violation of assumptions surrounding calculations of stage mortality may have large implications for the estimates of population growth rate. Uncertainty in the estimates of mortality rates for the settler stage was due to their rarity in the established populations, while the recruit stage exhibited large scatter around the shell length-mortality relationship. Simultaneous under- or overestimation of mortality in both these stages would have a larger impact on the population growth rate estimate, while errors in mortality estimates in opposite directions (e.g. recruit mortality overestimated and settler mortality underestimated, or vice versa) would have a smaller impact. While all demographic models simplify population dynamics to some degree, and given that our estimated vital rates came from observed patterns in nature, our model approach can effectively generate hypotheses about the population dynamics and life-history traits of vent species that can guide future experimental work in these remote habitats.

\section{Future applications}

Since their discovery in the late 1970s, investigation into ecological processes at deep-sea hydrothermal vents has proceeded slowly, due to the difficulties of working in these remote and dynamic environments. Such challenges should naturally lead to the use of 
models in vent research as tools to augment the understanding of biological assemblages, refine hypotheses and guide research efforts in these challenging deep-sea habitats (Shea et al. 2008). While our model represents a first attempt at describing population dynamics of a hydrothermal vent species, it also provides an example of the high potential of models, originally developed for use in other ecosystems, to accelerate research in deep-sea communities. As deep-sea technologies improve and more experimental data become available, this modeling approach can be utilized to investigate other aspects of the life history of Lepetodrilus fucensis, such as developing 2-sex models to investigate sex segregation in microhabitats (e.g. Bates 2008) or generating multiple matrices and using life-table response experiments to explore differences in the vital rates of populations in different microhabitats (e.g. Levin et al. 1996). Incorporating environmental stochasticity into the model would allow for examination of the response of vital rates to temporal variations in the external environment (Caswell 2001). Our model could be coupled to more complex ones, such as with integrodifference equations in discrete-time models (e.g. Neubert \& Caswell 2000) or metapopulation models (e.g. Neubert et al. 2006) that can link demographic data and dispersal.

Our approach could also be used to model the dynamics of other hydrothermal vent species or species in other chemosynthetic environments, as few parameters are needed to construct a population projection matrix. Lepetodrilus species are common gastropods at hydrothermal vents and cold seeps, but recent studies suggest $L$. fucensis is more highly specialized and possesses unique life-history traits compared to other members of the genus (e.g. Bates 2007a, Kelly \& Metaxas 2007). The possession of chemosynthetic episymbionts may be particularly important to its success, but may also render $L$. fucensis more dependent on fluid variations than species without symbionts. Compared to hydrothermal vent habitats, species inhabiting cold seeps experience markedly different spatial and temporal variations in fluid flow and scales of disturbance (Sibuet \& Olu 1998). Our model could be used to examine how chemoautotrophic symbioses may affect life-history traits and population dynamics of Lepetodrilus species in vents at different ocean basins or biogeographic provinces, as well as different chemosynthetic reducing habitats. In addition, our approach would also be useful to compare life-history traits of deep-water benthic invertebrate species to those in shallow-water environments that experience similar substantial gradients in disturbance, temperature or productivity (e.g. rocky intertidal zones).

\section{CONCLUSIONS}

In summary, the dynamics and characteristics of early life-history stages of Lepetodrilus fucensis appear to play a vital role in its persistence. Rapid growth, early maturation and frequent reproduction parallel life-history traits found in species adapted to other disturbed or variable habitats, yet $L$. fucensis appears to be unique in that recruit survival is also high. Because recruit survival is so important to population growth, the dynamics of this early life-history stage will be most influential to its success. However, biological interactions, such as density dependence or individual behaviour in response to environmental stimuli, may also be important in regulating its populations over time. Our analyses not only emphasize the possible combinations of life-history tactics of organisms in extreme and variable habitats, but also underscore the value in utilizing the hydrothermal vent system to examine life-history adaptations of marine organisms in ephemeral, harsh and variable ecosystems.

Acknowledgements. We thank C. T. Taggart, A. Neuheimer, D. Reed, R. Mirshak and 2 anonymous reviewers whose constructive comments helped strengthen this manuscript. This research was supported by a Natural Sciences and Engineering Research Council of Canada (NSERC) Postgraduate Scholarship (PGS D) and the Izaak Walton Killam Memorial Scholarship to N.K., and a NSERC Discovery grant to A.M.

\section{LITERATURE CITED}

Bates AE (2007a) Feeding strategy, morphological specialisation and presence of bacterial episymbionts in lepetodrilid gastropods from hydrothermal vents. Mar Ecol Prog Ser 347:87-99

> Bates AE (2007b) Persistence, morphology, and nutritional state of a gastropod hosted bacterial symbiosis in different levels of hydrothermal vent flux. Mar Biol 152:557-568

> Bates AE (2008) Size- and sex-based habitat partitioning by Lepetodrilus fucensis near hydrothermal vents on the Juan de Fuca Ridge, Northeast Pacific. Can J Fish Aquat Sci 65:2332-2341

Bates AE, Tunnicliffe V, Lee RW (2005) Role of thermal conditions in habitat selection by hydrothermal vent gastropods. Mar Ecol Prog Ser 305:1-15

Berg CJ (1985) Reproductive strategies of mollusks from abyssal hydrothermal vent communities. Bull Biol Soc Wash 6:185-197

Blower S, Roughgarden J (1987) Population dynamics and parasitic castration: a mathematical model. Am Nat 129: 730-754

Brault S, Caswell H (1993) Pod-specific demography of killer whales (Orcinus orca). Ecology 74:1444-1454

Butterfield DA, Lilley MD, Huber JA, Baross JA, Roe KK, Embley RW, Massoth GJ (2004) Mixing, reaction, and microbial activity in the sub-seafloor revealed by temporal and spatial variation in diffuse flow vents at Axial Volcano. In: Wilcock WSD, DeLong EF, Kelley DS, Baross JA, Cary SC (eds) The subseafloor biosphere at mid-ocean 
ridges. American Geophysical Union, Washington, DC, p 269-289

Caswell H (2001) Matrix population models. Sinauer Associates, Sunderland, MA

> Chase RL, Delaney JR, Karsten JL, Johnson HP and others (1985) Hydrothermal vents on an axis seamount of the Juan de Fuca Ridge. Nature 313:212-214

Chevaldonne P, Jollivet D, Vangriesheim A, Desbruyeres D (1997) Hydrothermal-vent alvinellid polychaete dispersal in the Eastern Pacific. 1. Influence of vent site distribution, bottom currents, and biological patterns. Limnol Oceanogr 42:67-80

Crouse DT, Crowder LB, Caswell H (1987) A stage-based population model for loggerhead sea turtles and implications for conservation. Ecology 68:1412-1423

$>$ Crowder LB, Crouse DT, Heppell SS, Martin TH (1994) Predicting the impact of turtle excluder devices on loggerhead sea turtle populations. Ecol Appl 4:437-445

de Burgh ME, Singla CL (1984) Bacterial colonization and endocytosis on the gill of a new limpet species from a hydrothermal vent. Mar Biol 84:1-6

de Kroon H, Plaisier A, van Groenendael J, Caswell H (1986) Elasticity: the relative contribution of demographic parameters to population growth rate. Ecology 67:1427-1431

Embley RW, Chadwick WW Jr, Clague D, Stakes D (1999) 1998 eruption of Axial Volcano: multibeam anomalies and sea-floor observations. Geophys Res Lett 26:3425-3428

Frazer NB (1987) Preliminary estimates of survivorship for wild juvenile loggerhead sea turtles (Caretta caretta). J Herpetol 21:232-235

Gibbs PE, Bryan GW (1986) Reproductive failure in populations of the dog-whelk, Nucella lapillus, caused by imposex induced by tributyltin from antifouling paints. J Mar Biol Assoc UK 66:767-777

> Haymon RM, Fornari DJ, Von Damm KL, Lilley MD and others (1993) Volcanic eruption of the mid-ocean ridge along the East Pacific Rise crest at $9^{\circ} 45-52^{\prime} \mathrm{N}$ : direct submersible observations of seafloor phenomena associated with an eruption event in April, 1991. Earth Planet Sci Lett 119:85-101

Higgins K, Hastings A, Botsford LW (1997) Density dependence and age structure: nonlinear dynamics and population behaviour. Am Nat 149:247-269

Horvitz CC, Schemske DW (1995) Spatiotemporal variation in demographic transitions of a tropical understory herb: projection matrix analysis. Ecol Monogr 65:155-192

Hunt HL, Scheibling RE (1997) Role of early post-settlement mortality in recruitment of benthic marine invertebrates. Mar Ecol Prog Ser 155:269-301

Jannasch HW, Mottl MJ (1985) Geomicrobiology of deep-sea hydrothermal vents. Science 229:717-723

Johnson KS, Childress JJ, Beehler CL (1988) Short-term temperature variability in the Rose Garden hydrothermal vent field: an unstable deep-sea environment. Deep-Sea Res A 35:1711-1721

Karl DM, Wirsen CO, Jannasch HW (1980) Deep-sea primary production at the Galapagos hydrothermal vents. Science 207:1345-1347

Kelly NE, Metaxas A (2007) Influence of habitat on the reproductive biology of the deep-sea hydrothermal vent limpet Lepetodrilus fucensis (Vetigastropoda: Mollusca) from the Northeast Pacific. Mar Biol 151:649-662

Kelly NE, Metaxas A (2008a) Population structure of two deep-sea hydrothermal vent gastropods from the Juan de Fuca Ridge, NE Pacific. Mar Biol 153:457-471

Kelly NE, Metaxas A (2008b) Diversity of invertebrate colonists on simple and complex substrates at hydrothermal vents on the Juan de Fuca Ridge. Aquat Biol 3:271-281
Kelly NE, Metaxas A, Butterfield D (2007) Spatial and temporal patterns of colonization by deep-sea hydrothermal vent invertebrates on the Juan de Fuca Ridge, NE Pacific. Aquat Biol 1:1-16

Koons DN, Grand JB, Zinner B, Rockwell RF (2005) Transient population dynamics: relations to life history and initial population state. Ecol Model 185:283-297

Lafferty KD (1993) Effects of parasitic castration on growth, reproduction and population dynamics of the marine snail Cerithidea californica. Mar Ecol Prog Ser 96:229-237

> Lavelle JW, Cannon GA (2001) On subinertial oscillations trapped by the Juan de Fuca Ridge, Northeast Pacific. J Geophys Res 106:31099-31116

- Lefkovitch LP (1965) The study of population growth in organisms grouped by stages. Biometrics 21:1-18

> Leslie PH (1945) On the use of matrices in certain population mathematics. Biometrika 33:183-212

Leslie PH (1948) Some further notes on the use of matrices in population mathematics. Biometrika 35:213-245

> Levesque C, Juniper SK, Marcus J (2003) Food resource partitioning and competition among alvinellid polychaetes of Juan de Fuca Ridge hydrothermal vents. Mar Ecol Prog Ser 246:173-182

> Levin LA, Huggett DV (1990) Implications of alternative reproductive modes for seasonality and demography in an estuarine polychaete. Ecology 71:2191-2208

> Levin L, Caswell H, Bridges T, DiBacco C, Cabrera D, Plaia G (1996) Demographic responses of estuarine polychaetes to pollutants: life-table response experiments. Ecol Appl 6: 1295-1313

Lima M, Brazeiro A, Defeo O (2000) Population dynamics of the yellow clam Mesodesma mactroides: recruitment variability, density-dependence and stochastic processes. Mar Ecol Prog Ser 207:97-108

Lo NCH, Smith PE, Butler JL (1995) Population growth of northern anchovy and Pacific sardine using stage-specific matrix models. Mar Ecol Prog Ser 127:15-26

Lutz RA, Fritz LW, Rhoads DC (1985) Molluscan growth at deep-sea hydrothermal vents. Bull Biol Soc Wash 6: 199-210

> Lutz RA, Shank TM, Fornari DJ, Haymon RM, Lilley MD, Von Damm KL, Desbruyeres D (1994) Rapid growth at deepsea vents. Nature 371:663-664

Marcus J, Tunnicliffe V, Butterfield DA (2009) Post-eruption succession of macrofaunal communities at diffuse flow hydrothermal vents on Axial Volcano, Juan de Fuca Ridge. Northeast Pacific. Deep-Sea Res II 56:1586-1598

> Marsh AG, Mullineaux LS, Young CM, Manahan DT (2001) Larval dispersal potential of the tubeworm Riftia pachyptila at deep-sea hydrothermal vents. Nature 411:77-80

McCann K, Shuter B (1997) Bioenergetics of life history strategies and the comparative allometry of reproduction. Can J Fish Aquat Sci 54:1289-1298

> McLean JH (1988) New archaeogastropod limpets from hydrothermal vents; Superfamily Lepetodrilacea I. Systematic descriptions. Philos Trans R Soc Lond B Biol Sci 319:1-32

Metaxas A (2004) Spatial and temporal patterns in larval supply at hydrothermal vents in the Northeast Pacific Ocean. Limnol Oceanogr 49:1949-1956

Micheli F, Peterson CH, Mullineaux LS, Fisher CR and others (2002) Predation structures communities at deep-sea hydrothermal vents. Ecol Monogr 72:365-382

Morgan SG (1995) Life and death in the plankton: larval mortality and adaptation. McEdward L (ed) Ecology of marine invertebrate larvae. CRC Press, Boca Raton, FL, p 279-322 
Mullineaux LS, Peterson CH, Micheli F, Mills SW (2003) Successional mechanism varies along a gradient in hydrothermal fluid flux at deep-sea vents. Ecol Monogr 73:523-542

Neubert MG, Caswell H (2000) Demography and dispersal: calculation and sensitivity analysis of invasion speed for structured populations. Ecology 81:1613-1628

Neubert MG, Mullineaux LS, Hill MF (2006) A metapopulation approach to interpreting diversity at deep-sea hydrothermal vents. In: Kritzer JP, Sale PF (eds) Marine metapopulations. Elsevier Academic Press, Burlington, MA, p 321-352

Pennycuick CJ, Compton RM, Beckingham L (1968) A computer model for simulating the growth of a population, or of two interacting populations. J Theor Biol 18:316-329

Pradillon F, Shillito B, Young CM, Gaill F (2001) Developmental arrest in vent worm embryos. Nature 413:698-699

Ramirez Llodra E (2002) Fecundity and life-history strategies in marine invertebrates. Adv Mar Biol 43:87-170

Sarrazin J, Juniper SK (1999) Biological characteristics of a hydrothermal edifice mosaic community. Mar Ecol Prog Ser 185:1-19

Sarrazin J, Robigou V, Juniper SK, Delaney JR (1997) Biological and geological dynamics over four years on a hightemperature sulfide structure at the Juan de Fuca Ridge hydrothermal observatory. Mar Ecol Prog Ser 153:5-24

Sarrazin J, Juniper SK, Massoth G, Legendre P (1999) Physi$\mathrm{cal}$ and chemical factors influencing species distributions on hydrothermal sulfide edifices of the Juan de Fuca Ridge, northeast Pacific. Mar Ecol Prog Ser 190:89-112

Shank TM, Fornari DJ, Von Damm KL, Lilley MD, Haymon RM, Lutz RA (1998) Temporal and spatial patterns of biological community development at nascent deep-sea hydrothermal vents. Deep-Sea Res II 45:465-515

Shea K, Metaxas A, Young CR, Fisher CR (2008) Processes and interactions in macrofaunal assemblages at hydrothermal vents: a modeling perspective. In: Lowell $\mathrm{R}$, Seewald, Metaxas A, Perfit M (eds) Magma to microbe: modeling hydrothermal processes at ocean spreading centers. American Geophysical Union, Washington, DC, p 259-274

Sibuet M, Olu K (1998) Biogeography, biodiversity and fluid dependence of deep-sea cold seep communities at active and passive margins. Deep-Sea Res II 45:517-567

Sondgerath D, Richter O (1990) An extension of the Leslie matrix model for describing population dynamics of species with several development stages. Biometrics 46: 595-607

Southwood TRE (1988) Tactics, strategies, and templets. Oikos 52:3-18

Editorial responsibility: Steven Morgan,

Bodega Bay, California, USA
Stearns SC (1992) The evolution of life histories. Oxford University Press, New York

Thompson RE, Mihaly SF, Rabinovich AB, McDuff RE, Veirs SR, Stahr ER (2003) Constrained circulation at Endeavour Ridge facilitates colonization by vent larvae. Nature 424:545-549

> Tivey MK, Bradley AM, Joyce TM, Kadko D (2002) Insights into tide-related variability at seafloor hydrothermal vents from time-series temperature measurements. Earth Planet Sci Lett 202:693-707

> Tracey GA (1988) Feeding reduction, reproductive failure, and mortality in Mytilus edulis during the 1985 'brown tide' in Narragansett Bay, Rhode Island. Mar Ecol Prog Ser 50:73-81

Tsurumi M, Tunnicliffe V (2001) Characteristics of a hydrothermal vent assemblage on a volcanically active segment of Juan de Fuca Ridge, Northeast Pacific. Can J Fish Aquat Sci 58:530-542

Tsurumi M, Tunnicliffe V (2003) Tubeworm-associated communities at hydrothermal vents on the Juan de Fuca Ridge, Northeast Pacific. Deep-Sea Res I 50:611-629

Tunnicliffe V, Juniper SK (1990) Dynamic character of the hydrothermal vent habitat and the nature of the sulphide chimney fauna. Prog Oceanogr 24:1-13

Tunnicliffe V, Garrett JF, Johnson HP (1990) Physical and biological factors affecting the behaviour and mortality of hydrothermal vent tubeworms (vestimentiferans). DeepSea Res A 37:103-125

> Tunnicliffe V, Embley RW, Holden JF, Butterfield DA, Massoth BJ, Juniper SK (1997) Biological colonization of new hydrothermal vents following an eruption on Juan de Fuca Ridge. Deep-Sea Res I 44:1627-1644

Tunnicliffe V, Rose J, Bates AE, Kelly NE (2008) Parasitization of a hydrothermal vent limpet (Lepetodrilidae, Vetigastropoda) by a highly modified copepod (Chitonophilidae, Cyclopoida). Parasitology 135:1281-1293

Usher MB (1971) Developments in the Leslie matrix model. In: Jeffers JNR (ed) Methematical models in ecology. Blackwell Scientific, London, p 29-60

Vandermeer JH (1975) On the construction of the population projection matrix for a population grouped in unequal stages. Biometrics 31:239-242

> Vaughan DS, Saila SB (1976) A method for determining mortality rates using the Leslie matrix. Trans Am Fish Soc 105:380-383

- Winemiller KO, Rose KA (1992) Patterns of life-history diversification in North American fishes: implications for population regulation. Can J Fish Aquat Sci 49: $2196-2218$

Submitted: May 13, 2009; Accepted: November 29, 2009 Proofs received from author(s): March 10, 2010 